\title{
Impact of foliar herbivory on the development of a root-feeding insect and its parasitoid
}

\author{
Roxina Soler • T. Martijn Bezemer • \\ Anne Marie Cortesero • Wim H. Van der Putten • \\ Louise E. M. Vet • Jeffrey A. Harvey
}

Received: 31 August 2006 / Revised: 8 November 2006 / Accepted: 11 December 2006 / Published online: 3 March 2007

(C) Springer-Verlag 2007

\begin{abstract}
The majority of studies exploring interactions between above- and below-ground biota have been focused on the effects of root-associated organisms on foliar herbivorous insects. This study examined the effects of foliar herbivory by Pieris brassicae L. (Lepidoptera: Pieridae) on the performance of the root herbivore Delia radicum L. (Diptera: Anthomyiidae) and its parasitoid Trybliographa rapae (Westwood) (Hymenoptera: Figitidae), mediated through a shared host plant Brassica nigra L. (Brassicaceae). In the presence of foliar herbivory, the survival of $D$. radicum and T. rapae decreased significantly by more than $50 \%$. In addition, newly emerged adults of both root herbivores and parasitoids were significantly smaller on plants that had been exposed to foliar herbivory than on control plants. To determine what factor(s) may have
\end{abstract}

R. Soler $(\bowtie) \cdot$ T. M. Bezemer · W. H. Van der Putten .

L. E. M. Vet · J. A. Harvey

Department of Multitrophic Interactions,

Netherlands Institute of Ecology (NIOO-KNAW),

P.O. Box 40, 6666 ZG Heteren, The Netherlands

e-mail: r.soler@nioo.knaw.nl

T. M. Bezemer · W. H. Van der Putten

Laboratory of Nematology,

Wageningen University and Research Centre,

P.O. Box 8123, 6700 ES Wageningen, The Netherlands

T. M. Bezemer · L. E. M. Vet

Laboratory of Entomology,

Wageningen University and Research Centre,

P.O. Box 8031, $6700 \mathrm{EH}$ Wageningen, The Netherlands

A. M. Cortesero

Laboratory of Ecobiology of Insect Parasitoids,

Rennes University, Avenue du General Leclerc,

35042 Rennes, France accounted for the observed results, we examined the effects of foliar herbivory on root quantity and quality. No significant differences in root biomass were found between plants with and without shoot herbivore damage. Moreover, concentrations of nitrogen in root tissues were also unaffected by shoot damage by $P$. brassicae larvae. However, higher levels of indole glucosinolates were measured in roots of plants exposed to foliar herbivory, suggesting that the development of the root herbivore and its parasitoid may be, at least partly, negatively affected by increased levels of these allelochemicals in root tissues. Our results show that foliar herbivores can affect the development not only of root-feeding insects but also their natural enemies. We argue that such indirect interactions between above- and below-ground biota may play an important role in the structuring and functioning of communities.

Keywords Above-/below-ground interactions - Delia radicum - Glucosinolates · Plant-insect interactions ·

Trybliographa rapae

\section{Introduction}

Over the past 20 years, studies exploring communitylevel processes have been based primarily on bi- and tri-trophic interactions in above-ground systems, usually involving associations among plants, insect herbivores, and their natural enemies such as parasitoids or predators (Price et al. 1980; Turlings et al. 1990; Vet and Dicke 1992; Dicke 1999). While providing valuable data on a range of selective forces shaping community structure and function, these studies have generally ignored biological processes that occur below-ground. 
Recently, however, it has become apparent that aboveground trophic interactions can be strongly influenced by interactions between the host plant and soil-dwelling organisms (Gange and Brown 1989; Masters and Brown 1992, 1997; Masters et al. 1993; Masters 1995; Gange 2001; Van der Putten et al. 2001; Bardgett and Wardle 2003; Bezemer et al. 2003). For instance, recent studies have shown that soil-dwelling organisms-such as root-feeding insects, arbuscular mycorrhiza fungi, and nematodes - can also influence the growth, development, and behavior of higher trophic levels belowground, including parasitoids (Masters et al. 2001; Gange et al. 2003; Wurst and Jones 2003; Bezemer et al. 2005; Guerrieri et al. 2005) and even hyperparasitoids in the fourth trophic level (Soler et al. 2005).

It is also known that above-ground herbivory can affect the development of below-ground insect herbivores (reviewed by Blossey and Hunt-Joshi 2003), when the shared host plant has previously been exposed to intense shoot damage. For example, Tindall and Stout (2001) reported that severe damage by insect foliar herbivores was correlated with a significant reduction in the body size of an insect herbivore feeding on root tissues of the same host plant, compared with conspecifics developing on roots of plants without foliar herbivores. Other studies have shown similar effects (Masters et al. 1993; Hunt-Joshi and Blossey 2005). However, the effects of foliar herbivory on the development of natural enemies in the soil, such as predators and parasitoids, remain largely unexplored.

Thus far, the effects of above-ground herbivory on the performance of below-ground consumers have been explained mainly by quantitative changes in the amount of root biomass, when an extreme amount of leaf damage results in partial or complete death of the root system. However, minor levels of shoot damage, while not leading to a significant reduction in root biomass, may still affect the quality of the root tissues influencing the development of root-associated organisms (reviewed in Bezemer and Van Dam 2005). Furthermore, interactions between above- and belowground herbivores may also be mediated by qualitative changes in the shared host plant. For example, insect herbivory frequently leads to a systemic defense response within the host plant, resulting in enhanced concentrations of secondary plant compounds in plant organs that have not been damaged by herbivory (Karban and Baldwin 1997). Secondary plant compounds commonly have a negative impact on herbivore performance (Karban and Baldwin 1997). Several studies have shown that root herbivory can result in enhanced concentrations of secondary plant compounds in the foliage, although the reverse, e.g., the effects of foliar herbivory on changes in concentrations of root secondary plant compounds, has rarely been reported (reviewed in Bezemer and Van Dam 2005). Moreover, herbivory can induce a stress response within the host plant, which can lead to a reallocation of plant compounds such as carbohydrates and soluble nitrogen between root and shoot tissues, and the concentration of these compounds is known to directly affect insect growth parameters (Masters et al. 1993; Masters and Brown 1997). It is important to stress that the mechanisms described above are not necessarily mutually exclusive.

In this study, we examined the effects of aboveground herbivory on the development and survival of a below-ground insect herbivore and its endoparasitoid. Our study is based on interactions involving a naturally occurring system in Western Europe. The black mustard, Brassica nigra L. (Brassicaceae), is a widely distributed annual crucifer that is common along rivers and on disturbed sites in The Netherlands (Schaminee et al. 1998). It is attacked by several adapted specialist herbivores, including the large cabbage white butterfly, Pieris brassicae L. (Lepidoptera: Pieridae) whose larvae feed on the shoots and flowers of this and related species (Harvey et al. 2003). Mustard plants are also attacked by specialized root-feeding herbivores, including the cabbage root fly, Delia radicum L. (Diptera: Anthomyiidae) (Coaker and Finch 1971). Trybliographa rapae (Westwood) (Hymenoptera: Figitidae) is one of the main parasitoids of D. radicum in Europe (Lahmar 1982). The main aim of this investigation was to determine whether the growth, development, and survival of $D$. radicum and its endoparasitoid, T. rapae, are affected by foliar herbivory by $P$. brassicae. We also examined whether above-ground herbivory leads to qualitative and/or quantitative differences in root tissues. We compared levels of root biomass in plants with and without shoot damage, as well as levels of nitrogen in root tissues. Finally, we compared levels of allelochemicals (glucosinolates) in root tissues of plants under the two treatments. We hypothesized that above-ground herbivory by $P$. brassicae would result in reduced root-plant quality which would negatively affect the performance of $D$. radicum. Because T. rapae is a koinobiont parasitoid, $D$. radicum larvae continue feeding and growing during much of the parasitoidhost interaction (reviewed in Harvey 2005). As a consequence of this close association between host and parasitoid, we hypothesized that the effects of $P$. brassicae on D. radicum would be carried over to T. rapae. Since parasitoids are highly susceptible to very small changes in the quality of the hosts, the effect on the parasitoid should be stronger than that on the host. 


\section{Materials and methods}

\section{Studied species}

Brassica nigra, like other members of the Brassicaceae, possesses potent inducible direct defenses via the production of glucosinolates and their breakdown products; thus, the plant provides excellent potential for the study of multitrophic interactions (Van Dam et al. 2003). Pieris brassicae is a specialist chewing foliar herbivore that feeds on several species of wild and cultivated crucifers. The female butterfly typically lays broods of 7-140 eggs on the underside of a leaf. After hatching, the larvae feed gregariously until the third instar, when they disperse on the food plant. Delia radicum is a specialist chewing root herbivore that feeds on several species of crucifers. Females oviposit near the root-stem interface. The newly hatched maggots feed by boring galleries in the upper roots of the plant. Trybliographa rapae is a fairly specialized solitary koinobiont endoparasitoid that parasitizes L1-L3 instar larvae of $D$. radicum, as well as several closely related species. Adult parasitoid females forage via antennation, ovipositor probing, and vibrotaxis in order to find their hosts (Vet and Van Alphen 1985). The wasps readily parasitize larvae that are actively feeding in the root galleries but refuse hosts extracted from the root (Jones 1986). Females use their sharp, but flexible, ovipositor to explore infested roots to find hosts and evaluate their quality (Neveu et al. 2000).

Seeds of B. nigra were collected from a single population in the Northwest of Wageningen, The Netherlands. Seeds were surface sterilized and germinated on a bed of glass pearls (pearls of $1 \mathrm{~mm}$ diameter). One week after germination, seedlings were transplanted into 1.2-1 pots, filled with soil collected from a restoration area that was abandoned in 1996, at De Mossel in Ede, The Netherlands. The sandy loam soil was sieved $(2 \mathrm{~cm})$ and mixed with $10 \%$ white sand (to improve the drainage of the soil), and sterilized using gamma radiation (25 KGray) to eliminate all soil organisms. The plants were grown in a greenhouse, at $70 \%$ relative humidity, at $22 \pm 1{ }^{\circ} \mathrm{C}$ (day) and $16 \pm 1{ }^{\circ} \mathrm{C}$ (night) on a 16-h:8-h day:night cycle. Natural daylight was provided by metal halide lamps $\left(225 \mu \mathrm{mol} \mathrm{s}{ }^{-1} \mathrm{~m}^{-2}\right.$ PAR; 1 lamp per $1.5 \mathrm{~m}^{2}$ ). Plants were watered daily and supplemented with nutrients (Hoagland solution) once when the plants were 3 weeks old. Pieris brassicae was obtained from the insect culture maintained at the Laboratory of Entomology of Wageningen University, The Netherlands. D. radicum and T. rapae were obtained from insect cultures maintained at the Laboratory of Ecobiology of Insect Parasitoids, of Rennes University, France.
Experimental design and insect measurements

To test the effect of above-ground herbivores on the performance of soil insects, we reared $D$. radicum and its parasitoid $T$. rapae on roots of plants previously exposed (treatment) and not exposed (control) to $P$. brassicae larvae. Twenty-five days after transplanting, three newly hatched L1 larvae of $P$. brassicae were carefully placed with a small brush on the youngest fully developed leaf of each plant, and enclosed in a cylindrical clip cage ( $5.5 \mathrm{~cm}$ diameter) in order to ensure that the damage was localized. After 3 days, the larvae were moved to another new leaf on the plant. The larvae were allowed to feed for a further 3 days, after which each larva and clip cage was removed. Thus, each foliardamaged plant was exposed to feeding by three L1 $P$. brassicae larvae for a total of 6 days. A second set of plants was kept undamaged and served as control. To standardize the possible effects of the clip cages on plant shoots, they were also placed on control plants, following the same methods as for the foliar-damaged plants. A total of 72 plants were used in the experiment (36 plants with and 36 without foliar herbivore damage).

One day after removing the $P$. brassicae larvae, four L1 $D$. radicum larvae were introduced to each plant by carefully placing the larvae with a brush onto the soil surface immediately adjacent to the stem. Using a magnifying glass, each plant was carefully checked $30 \mathrm{~min}$ after inoculation, to ensure that all the root fly larvae had successfully entered into the soil. For each plant, two of the larvae were healthy and two had been parasitized by T. rapae within approximately the prior $12 \mathrm{~h}$. In a previous study, we reported that there was no significant difference in final root biomass in $B$. nigra plants with initial densities of five unparasitized $D$. radicum larvae per plant when compared with undamaged plants (Soler at al. 2005). Furthermore, parasitized larvae consume less plant material and attain smaller final masses than healthy hosts (Grandgirard 2003); thus, we assumed that plant root biomass would not be a limiting factor for root herbivore/parasitoid development. It is also important to stress that larvae of $D$. radicum are not cannibalistic (A.M. Cortesero, unpublished observations), making it possible for unparasitized and parasitized larvae to share a host plant.

To obtain parasitized D. radicum larvae, approximately 300 first instar larvae were offered to 60 mated T. rapae females over the course of $4 \mathrm{~h}$. To facilitate and ensure high rates of parasitism, a slice of $B$. napus (turnip) root of $1.5-2 \mathrm{~cm}$ in height $(15 \mathrm{~cm}$ diameter) that had previously been infested with the larvae of $D$. radicum was offered to the parasitoid females. The larvae were collected from the root after $4 \mathrm{~h}$, and 144 
larvae were then transferred to the experimental $B$. nigra plants. Because direct observations of parasitism are almost impossible in T. rapae, 100 additional larvae from the infested turnip slice were removed and placed on a new turnip, where parasitoid emergence was monitored. From these 100 larvae, 92 T. rapae adults emerged, and none produced $D$. radicum adults.

Following the below-ground inoculation of unparasitized and parasitized D. radicum larvae, experimental plants were placed individually into large meshed cylindrical cages (height $1 \mathrm{~m}$, diameter $35 \mathrm{~cm}$ ) to ensure that newly emerged adult flies and wasps did not escape and could be immediately captured. Plants from the two treatments were randomly distributed in the greenhouse and were moved around the room every 23 days to avoid any potential effects of positioning on insect development. The cages were checked twice daily (once in the morning and once in the afternoon) to record the emergence of adult flies and parasitoids. Newly emerged adults of $D$. radicum and $T$. rapae were collected with an aspirator. At emergence, the following data were recorded: (1) development time between inoculation and adult eclosion in days and (2) adult body size, based on the measurement of hind tibia length in both the herbivore and parasitoid. Hind tibia length has been commonly used as a measure of adult size in many insects, especially parasitoids (Godfray 1994; Harvey et al. 1994; Bezemer and Mills 2003). The hind tibia lengths of $D$. radicum and T. rapae were measured using a calibrated slide under a stereomicroscope. Adult survival (calculated as the proportion of insects that emerged relative to the number of larvae introduced in each pot) was also recorded.

\section{Plant responses}

Because the measurement of glucosinolate and nitrogen concentrations requires the destructive sampling of plants, root samples were taken from an additional set of plants (nine plants per treatment). The plants in the additional set were treated in exactly the same way as the foliar-damaged and control plants described above. Root material was collected $1 \mathrm{~h}$ before the other set of experimental plants was inoculated with parasitized and unparasitized $D$. radicum larvae to evaluate the quality of the control and foliar-damaged plants that larvae encountered after inoculation. After carefully washing the roots of each plant, the fine roots were separated from the main root. Roots less than $1 \mathrm{~mm}$ thick were considered fine (with a hair-like appearance) and those thicker than $1 \mathrm{~mm}$ were considered to be main roots. The roots were immediately frozen at $-80^{\circ} \mathrm{C}$, then freeze-dried and ground. Glucosinolate contents were determined using high performance liquid chromatography (HPLC) as described by Van Dam et al. (2004). Nitrogen content was determined using a Carlo Erba/Fisons, type EA1108, CHN analyzer. The total root biomass of the experimental plants was determined at the end of the experiment. The roots of each plant were harvested, oven-dried at $70^{\circ} \mathrm{C}$ and, subsequently, weighed on a microbalance.

\section{Statistical analysis}

The effects of foliar herbivory (with or without) and larval status (parasitized or unparasitized) on survival of $D$. radicum and $T$. rapae were tested using a generalized linear mixed model (with binomial distribution and logit link function, including plant as random term). The effects of foliar herbivory on developmental time and hind tibia length of $D$. radicum and $T$. rapae were tested using a generalized linear model (with normal distribution and identity link function). The effects of foliar herbivory and root type (primary or secondary roots) on plant quality (nitrogen and glucosinolate levels) were tested using a linear mixed model, including plant as random term to consider that the fine and main roots were sampled from the same plants. To test the effect of foliar herbivory on plant quantity (root biomass), we used analysis of variance. Normality, independence, and homogeneity of variance were checked by inspection of the residuals after model fitting. Analyses were carried out in Statistica and Genstat.

\section{Results}

Foliar herbivory significantly affected the survival of the root herbivore $D$. radicum and its parasitoid $T$. rapae $($ Wald $=12.17, P<0.001)$. Relative to control plants, the survival of $D$. radicum and $T$. rapae decreased by more than $50 \%$, when the host plants were previously exposed to foliar herbivory (Fig. 1), and the effect was qualitatively similar for root herbivore and parasitoid responses indicated by a non-significant interaction term (Wald $=0.49, P=0.48$ ). There was a significant effect of foliar herbivory on $D$. radicum and T. rapae adult size, measured as hind tibia length (Wald $=5.88, P=0.02$ ). Both herbivore and parasitoid adult sizes were reduced in the presence of foliar herbivores on the shared host plant (Fig. 2). Again, the negative effect of foliar herbivory did not differ between host and parasitoid (interaction term Wald $=0.02, P=0.86$ ). Development times of $D$. radicum and $T$. rapae were not significantly affected by foliar herbivory (Wald $=3.34, P=0.07$ ). 


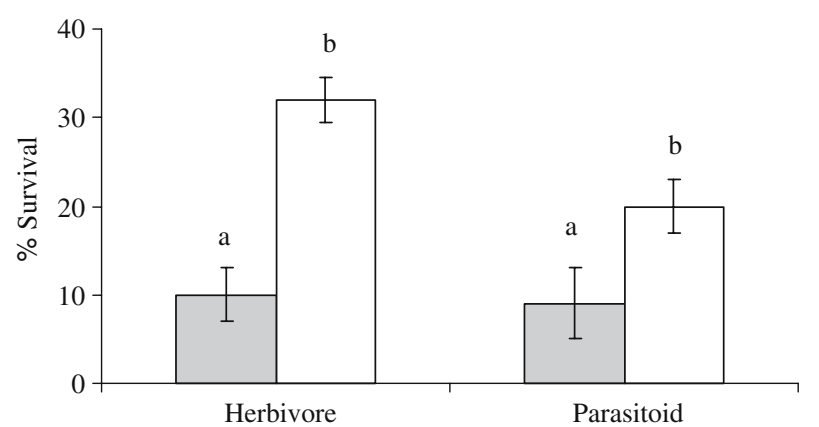

Fig. 1 Mean $( \pm \mathrm{SE})$ survival of $D$. radicum (herbivore) and $T$. rapae (parasitoid) on B. nigra plants that had been exposed to foliar herbivory (by P. brassicae) (shaded bars), and on control plants (open bars). Within herbivore and parasitoid, significant differences $(P<0.05)$ between treatments are indicated by different letters

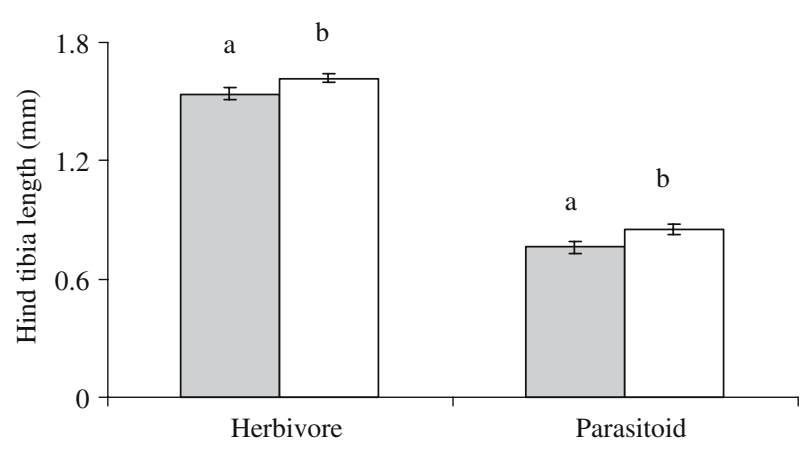

Fig. 2 Mean $( \pm \mathrm{SE})$ hind tibia length of $D$. radicum (herbivore) and $T$. rapae (parasitoid) on B. nigra plants that had been exposed to foliar herbivory (by P. brassicae) (shaded bars), and on control plants (open bars). Within herbivore and parasitoid, significant differences $(P<0.05)$ between treatments are indicated by different letters

Plants under both treatments demonstrated similar root biomass $\left(F_{1,30}=0.008, P=0.92\right.$; Fig. 3a). Rootnitrogen levels also did not differ significantly between control plants and plants exposed to foliar herbivory (Table 1). Independent of the treatment, nitrogen levels were significantly lower in secondary than in primary roots (Table 1 ). Foliar herbivory significantly affected the levels of indole glucosinolates (neoglucobrassicin and glucobrassicin) in the roots (Table 1). In the presence of foliar herbivory, the levels of neoglucobrassicin (Fig. 4a) and glucobrassicin (Fig. 4b) signifi-
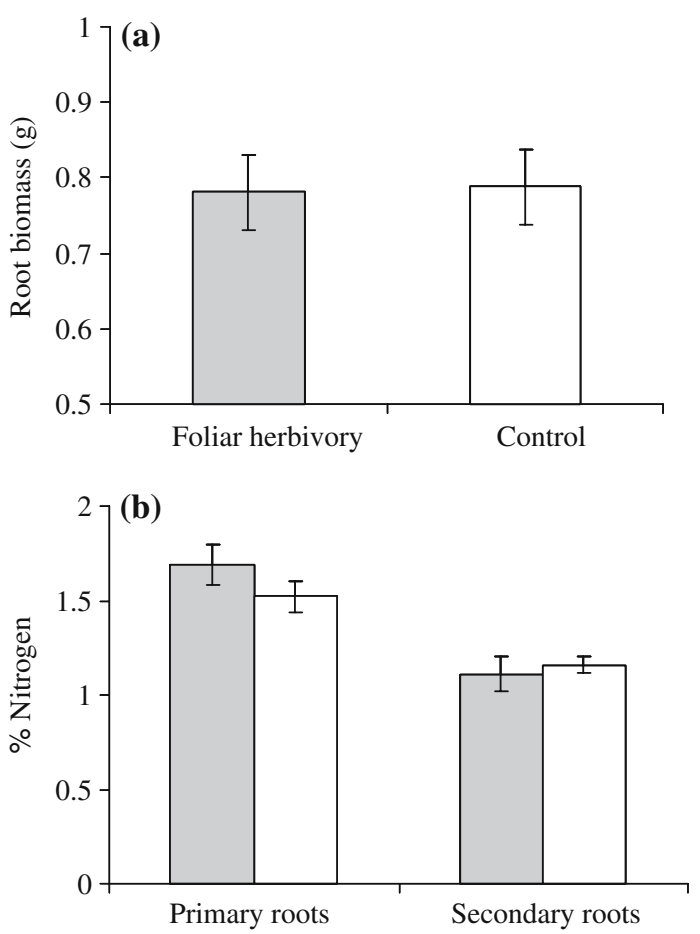

Fig. 3 Mean $( \pm \mathrm{SE})$ root biomass (a) and percentage of nitrogen in primary and secondary roots (b) of Brassica nigra plants that had been exposed to foliar herbivory (by P. brassicae) (shaded bars) and in those of control plants (open bars)

cantly increased in both primary and secondary roots. Independent of the treatment, levels of neoglucobrassicin and glucobrassicin were significantly higher in secondary than in primary roots. Concentrations of gluconasturtin (Fig. 4c) and sinigrin (Fig. 4d) did not differ significantly between the roots of control plants and plants that had been exposed to foliar herbivory (Table 1). Independent of the treatment, gluconasturtin levels were significantly higher in primary than in secondary roots. Sinigrin levels did not differ significantly between primary and secondary roots.

\section{Discussion}

This study provides evidence that shoot-feeding insects, via systemic changes in the root quality of the shared host plant, can influence the development of

Table 1 Approximate $F$-test ( $F$ and $P$ values) for the fixed effects and variance component estimates from REML (restricted maximum likelihood); analysis of the effect of foliar herbivory (by P. brassicae) and root-type on nitrogen and glucosinolate levels of $B$. nigra roots

\begin{tabular}{|c|c|c|c|c|c|c|c|c|c|c|}
\hline \multirow[t]{2}{*}{ Factors } & \multicolumn{2}{|c|}{ Nitrogen } & \multicolumn{2}{|c|}{ Neoglucobrassicin } & \multicolumn{2}{|c|}{ Glucobrassicin } & \multicolumn{2}{|c|}{ Gluconasturtin } & \multicolumn{2}{|c|}{ Sinigrin } \\
\hline & $F$ & $P$ & $F$ & $P$ & $F$ & $P$ & $F$ & $P$ & $F$ & $P$ \\
\hline Foliar herbivory (1) & 1.6 & 0.2 & 15.0 & $<0.001$ & 15.3 & $<0.001$ & 0.5 & 0.4 & 1.7 & 0.2 \\
\hline Root-type (2) & 28.4 & $<0.001$ & 28.5 & $<0.001$ & 89.5 & $<0.001$ & 4.57 & 0.03 & 0.001 & 0.9 \\
\hline Interaction (1.2) & 0.4 & 0.5 & 2.9 & 0.08 & 0.2 & 0.5 & 0.7 & 0.3 & 1.4 & 0.2 \\
\hline
\end{tabular}



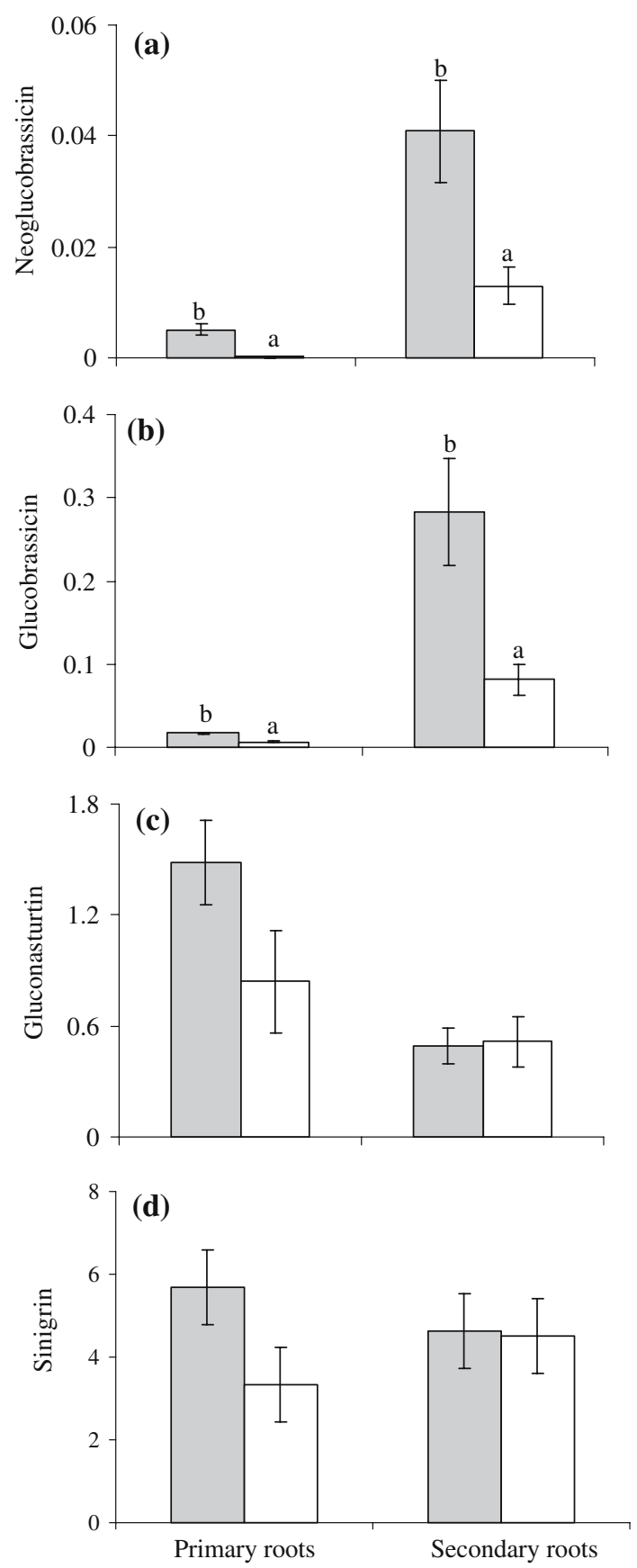

Fig. 4 Mean ( \pm SE) levels of glucosinolates ( $\mu \mathrm{mol} \mathrm{g}^{-1}$ dry mass) (a neoglucobrassicin, b glucobrassicin, c gluconasturtin, d sinigrin) in primary and secondary roots of Brassica nigra plants exposed to foliar herbivory (by $P$. brassicae) (shaded bars) and in those of control plants (open bars). Within each root type, significant differences $(P<0.05)$ between treatments are indicated by different letters

root-feeding insects sharing the host plant. Moreover, the effects can be carried over at least one trophic level higher, affecting the performance of a parasitoid. We found that foliar herbivory was significantly correlated with a reduction in successful development of Delia radicum and Trybliographa rapae. Survival of the herbivore and its parasitoid was two to three times higher on plants that were undamaged above-ground than on plants that were previously exposed to foliar herbivory. In addition, when compared with those on control plants, newly emerged adult $D$. radicum and $T$. rapae were significantly smaller when the insects developed on plants that had been initially damaged by foliar herbivores. Several authors have argued that body size is the main target of selection in parasitoids and other insects, because it is correlated with life-history and demographic characters such as searching and mating efficiency, longevity, and fecundity (Godfray 1994; Harvey et al. 1994; Bezemer and Mills 2003; Harvey 2005). Consequently, our results reveal not only that $D$. radicum and $T$. rapae suffer from increased mortality on plants previously exposed to foliar herbivory compared with control plants, but that fitness of the surviving adults is also compromised.

In a recent study based on the same multitrophic system, we reported that root herbivory by $D$. radicum reduced the performance of the foliar feeder $P$. brassicae (Soler et al. 2005). However, several others found no significant relationship between root herbivory and the performance of above-ground herbivores (Moran and Whitham 1990; Salt et al. 1996; Hunt-Joshi and Blossey 2005), and yet others found a positive relationship (Masters and Brown 1992). These results clearly show that the effects of below-ground herbivores on their above-ground counterparts are likely to be association-specific, although this contrasts with the rather consistent negative effect thus far observed in most reciprocal studies of above-ground herbivory on below-ground insects (this study; Moran and Whitham 1990; Masters and Brown 1992; Salt et al. 1996; Tindall and Stout 2001; Hunt-Joshi and Blossey 2005). More work is clearly required to elucidate possible patterns in interactions between above- and below-ground systems, and to determine whether there are any clear patterns emerging from them.

We also found that the amount of root biomass did not differ significantly between the foliar-damaged and control plants, suggesting that the negative effects of above-ground herbivory by $P$. brassicae on the development of $D$. radicum and $T$. rapae were based on qualitative, rather than quantitative, changes in the root system. Because only three young caterpillars were allowed to feed from the foliage for a limited period of time, the physical amount of shoot tissue removed was negligible (R. Soler, personal observation). Changes in root biomass as a result of sourcesink relationships within the plant are likely to occur when above-ground herbivore damage is much more extensive (Hunt-Joshi and Blossey 2005). Root nitrogen 
levels were also not significantly affected by foliar herbivory, and thus it is highly unlikely that changes in this important (and often limiting) primary plant compound were responsible for the observed effects.

However, levels of indole glucosinolates were significantly increased by about $30 \%$ in plants that had been exposed to foliar herbivores. Glucosinolates and their breakdown products, including indoles, have been shown to be involved in reducing plant quality for both generalist and specialist insect herbivores and nematodes ( $\mathrm{Li}$ et al. 2000; Van Dam et al. 2005). Although indoles constituted only a small fraction of total glucosinolates in the plant (with sinigrin being by far the most prevalent), studies with other secondary compounds have shown that only trace amounts in the diet are required to exert strong effects on the development of herbivores and their parasitoids (Barbosa et al. 1986). Consequently, the negative relationship between above-ground herbivory and the development of $D$. radicum may be, at least partially, correlated with increased levels of indole glucosinolates in the roots of the shared host plant that were induced by feeding damage from $P$. brassicae larvae above ground.

It has been well established that allelochemicals in the herbivore's diet can exhibit negative effects on the morphology, development, size, and survival of their predators and parasitoids (reviewed in Harvey 2005; Ode 2006). T. rapae is a koinobiont parasitoid of $D$. radicum and, therefore, after being parasitized, Delia larvae continue feeding and growing until the final larval instar has been reached. At this time, the developing parasitoid larvae begin destructive feeding and exponential growth (Harvey et al. 1994). At the end of the host's larval development, allelochemicals that may be present in the hemolymph and other tissues, such as fat body, are rapidly consumed by the koinobiont parasitoid (Harvey 2005). Due to the tight linkage between host and koinobiont parasitoid development, in our study, increased mortality and reduced adult size observed in the T. rapae adults on plants that had been exposed to foliar herbivory could probably be attributed to a corresponding increased mortality and reduced size of its host $D$. radicum. Parasitoids, in particular, are highly susceptible to very small changes in the quality of the host's internal biochemical environment (Harvey 2005). Other studies have shown that parasitoids can be more affected than their hosts by the quality of the host plant (Harvey et al. 2003; Soler et al. 2005). This appears not to be the case in our studied trophic chain, since we found comparable effects of foliar herbivory on the root herbivore and its parasitoid.

In summary, this study has reported that herbivore damage of plant shoots can have significant negative effects on the development of below-ground herbivores and their natural enemies. Combined with the results of a previous study based on the same system, we have demonstrated that these effects are largely reciprocal (Soler et al. 2005). Our research further highlights the importance of integrating the below-ground domain with above-ground systems in order to better understand the myriad of factors that shape the evolution, assembly, and functioning of communities and ecosystems (Wardle et al. 2005). Studies over larger spatial scales have already shown that above-ground herbivores can influence the community structure of the below-ground system and vice-versa (De Deyn and Van der Putten 2005; Wardle et al. 2004). Further studies, combining interactions between above-ground and below-ground communities in a multitrophic framework, and which seek to explore both processes and mechanisms, are required if we are to develop a better understanding of the many complex factors that influence community structure and function.

Acknowledgments The authors wish to thank Antonin Ferry at Rennes University for sharing his expertise on the parasitoidrearing and for constructive comments during the experiment; Leo Koopman at Wageningen University for supplying the foliarherbivore cultures; Gregor Disveld for assistance in maintenance of plants; Ciska Raaijmakers for assistance in the glucosinolate extractions; and Eef Velthorst at Wageningen University for the $\mathrm{N}$-contents determination. The experiments were carried out in the Netherlands and complied with the current laws of the country. NIOO-KNAW publication 3869.

\section{References}

Barbosa P, Saunders JA, Kemper J, Trumbule R, Olechno J, Martinat P (1986) Plant allelochemicals and insect parasitoids effects of nicotine on Cotesia congregata (Say) (Hymenoptera, Braconidae) and Hyposoter annulipes (Cresson) (Hymenoptera, Ichneumonidae). J Chem Ecol 2:1319-1328

Bardgett RD, Wardle DA (2003) Herbivore-mediated linkages between aboveground and aboveground communities. Ecology 84:2258-2268

Bezemer TM, Mills NJ (2003) Clutch size decisions of a gregarious parasitoid under laboratory and field conditions. Anim Behav 66:1119-1128

Bezemer TM, Van Dam NM (2005) Linking aboveground and belowground interactions via induced plant defenses. Trends Ecol Evol 20:617-624

Bezemer TM, Wagenaar R, Van Dam NM, Wäckers FL (2003) Interactions between above- and belowground insect herbivores as mediated by the plant defense system. Oikos 101:555-562

Bezemer TM, De Deyn GB, Bossinga TM, Van Dam NM, Harvey JA, Van der Putten WH (2005) Soil community composition drives aboveground plant-herbivore-parasitoid interactions. Ecol Lett 8:652-661

Blossey B, Hunt-Joshi TR (2003) Belowground herbivory by insects: influence on plants and aboveground herbivores. Annu Rev Entomol 48:521-547 
Coaker TH, Finch S (1971) The cabbage root fly Erioischia brassicae (Bouche). Report of the National Vegetables Research Station for 1970

De Deyn GB, Van der Putten WH (2005) Linking aboveground and belowground diversity. Trends Ecol Evol 20:625-633

Dicke M (1999) Are herbivore-induced plant volatiles reliable indicators of herbivore identity to foraging carnivorous arthropods? Entomol Exp Appl 91:131-142

Gange AC (2001) Species-specific responses of a root- and shootfeeding insect to arbuscular mycorrhizal colonization of its host plant. New Phytol 150:611-618

Gange AC, Brown VK (1989) Effects of root herbivory by an insect on a foliar-feeding species, mediated through changes in the host plant. Oecologia 81:38-42

Gange AC, Brown VK, Aplin DM (2003) Multitrophic links between arbuscular mycorrhizal fungi and insect parasitoids. Ecol Lett 6:1051-1055

Godfray HCJ (1994) Parasitoids. Behavioral and evolutionary ecology. Princeton University Press, New Jersey

Grandgirard J (2003) Location and exploitation of host patches by the parasitoid Trybliographa rapae W (Hymenoptera: Figitidae): theoretical approach and applications to the biological control of the cabbage root fly Delia radicum (Diptera: Anthomyiidae). PhD thesis, University of Rennes 1 (France)

Guerrieri E, Lingua G, Digilio MC, Massa N, Berta G (2005) Do interactions between plant roots and the rhizosphere affect parasitoid behaviour? Ecol Entomol 30:128-128

Harvey JA (2005) Factors affecting the evolution of development strategies in parasitoid wasps: the importance of functional constraints and incorporating complexity. Entomol Exp Appl 117:1-13

Harvey JA, Harvey IF, Thompson DJ (1994) Flexible larval growth allows use of a range of host sizes by a parasitoid wasp. Ecology 75:1420-1428

Harvey JA, van Dam NM, Gols R (2003) Interactions over four trophic levels: foodplant quality affects development of a hyperparasitoid as mediated through a herbivore and its primary parasitoid. J Anim Ecol 72:520-531

Hunt-Joshi TR, Blossey B (2005). Interactions of root and leaf herbivores on purple loosestrife (Lythrum salicaria). Oecologia 142:554-563

Jones TH (1986) Patterns of parasitism by Trybliographa rapae (Westw.), a cynipid parasitoid of the cabbage root fly. PhD thesis, Imperial College, University of London

Karban R, Baldwin IT (1997) Induced responses to herbivory (interspecific interactions). University of Chicago Press, Chicago

Lahmar M (1982) Contribution á l'étitude de la biologie de la mouche du chou: Hylemya brassicae Bouché (Diptera:Anthomyiidae) dans les conditions de l'ouest de la France. PhD thesis, University of Rennes 1 (France)

Li Q, Eigenbrode SD, Stringham GR, Thiagarajah MR (2000) Feeding and growth of Plutella xylostella and Spodoptera eridania on Brassica juncea with varying glucosinolate concentrations and myrosinase activities. J Chem Ecol 26:24012419

Masters GJ (1995) The impact of root herbivory on aphid performance: field and laboratory evidence. Acta Oecol 16:135-142

Masters GJ, Brown VK (1992) Plant-mediated interactions between two spatially separated insects. Funct Ecol 6:175-179

Masters GJ, Brown VK (1997) Host-plant mediated interactions between spatially separated herbivores: effects on community structure. In: Gange AC, Brown VK (eds) Multitrophic interactions in a changing world. 36th symposium of the British ecological society. Blackwell, Oxford, pp 217232
Masters GJ, Brown VK, Gange AC (1993) Plant mediated interactions between above- and belowground insect herbivores. Oikos 66:148-151

Masters GJ, Jones TH, Rogers M (2001) Host-plant mediated effects of root herbivory on insect seed predators and their parasitoids. Oecologia 127:246-250

Moran NA, Whitham TG (1990) Interspecific competition between root-feeding and leaf-galling aphids mediated by hostplant resistance. Ecology 71:1050-1058

Neveu N, Krespi L, Kacem N, Nenon JP (2000) Host-stage selection by Trybliographa rapae, a parasitoid of the cabbage root fly Delia radicum. Entomol Exp Appl 96:231-237

Ode PJ (2006) Plant chemistry and natural enemy fitness: effects on herbivore and natural enemy interactions. Annu Rev Entomol 51:163-185

Price PW, Bouton CE, Gross P, McPheron BA, Thompson JN, Weis AE (1980) Interactions among three trophic levelsinfluence of plants on interactions between insect herbivores and natural enemies. Annu Rev Ecol Syst 11:41-65

Salt DT, Fenwick P, Whittaker JB (1996) Interspecific herbivore interactions in a high $\mathrm{CO} 2$ environment: root and shoot aphids feeding on Cardamine. Oikos 77:326-330

Schaminee JHJ, Weede EJ, Westhoff V (1998) De vegetatie van Netherland. Deel 4. Plantengemeenschappen van de kust en van binnenlandse pioniersmilieus. Opulus Press, Uppsala

Soler R, Bezemer TM, Van der Putten WH, Vet LEM, Harvey JA (2005) Root herbivore effects on above-ground herbivore, parasitoid and hyperparasitoid performance via changes in plant quality. J Anim Ecol 74:1121-1130

Tindall KV, Stout MJ (2001) Plant-mediated interactions between the rice water weevil and fall armyworm in rice. Entomol Exp Appl 101:9-17

Turlings TCJ, Tumlinson JH, Lewis WJ (1990) Exploitation of herbivore-induced plant odors by host-seeking parasitic wasps. Science 250:1251-1253

Van Dam NM, Harvey JA, Wäckers FL, Bezemer TM, Van der Putten WH, Vet LEM (2003) Interactions between aboveground and belowground induced responses against phytophages. Basic Appl Ecol 4:63-77

Van Dam NM, Witjes L, Svatos A (2004) Interactions between aboveground and belowground induction of glucosinolates in two wild Brassica species. New Phytol 161:801-810

Van Dam NM, Raaijmakers CE, van der Putten WH (2005) Root herbivory reduces growth and survival of the shoot feeding specialist Pieris rapae on Brassica nigra. Entomol Exp Appl 115:161-170

Van der Putten WH, Vet LEM, Harvey JA, Wäckers FL (2001) Linking above- and belowground multitrophic interactions of plants, herbivores, pathogens, and their antagonists. Trends Ecol Evol 16:547-554

Vet LEM, Dicke M (1992) Ecology of infochemical use by natural enemies in a tritrophic context. Annu Rev Entomol 37:141-172

Vet LEM, Van Alphen JJM (1985) A comparative functional-approach to the host detection behavior of parasitic wasps a qualitative study on Eucoilidae and Alysiinae. Oikos 44:478-486

Wardle DA, Yeates GW, Williamson WM, Bonner KI, Barker GM (2004) Linking aboveground and belowground communities: the indirect influence of aphid species identity and diversity on a three trophic level soil food web. Oikos 107:283-294

Wardle DA, Williamson WM, Yeates GW, Bonner KI (2005) Trickle-down effects of aboveground trophic cascades on the soil food web. Oikos 111:348-358

Wurst S, Jones TH (2003) Indirect effects of earthworms (Aporrectodea caliginosa) on an above-ground tritrophic interaction. Pedobiologia 47:91-97 